\title{
"Authoritarianism" of the left and the right
}

\author{
WARNER WILSON \\ Wright State University, Dayton, Ohio 45491 \\ LARRY DENNIS \\ University of Alabama, University, Alabama 35486 \\ and \\ ALLEN P. WADSWORTH, JR. \\ VA Hospital, Tuscaloosa, Alabama 35402
}

\begin{abstract}
One-hundred and fifteen students enrolled in psychology and sociology courses at the University of Alabama responded to several measures including (a) the California F scale, (b) a measure of liking for militant students, Negroes, and the NAACP, and of disliking for police, the U. S. military, and college administrators, and (c) a measure of disliking for militant students, Negroes, and the NAACP, and of liking for police, the U.S. military, and college administrators. The second and third measures were viewed as measures of left-wing and right-wing prejudice, respectively. The F scale correlated .70 with right-wing prejudice and -.25 with left-wing prejudice. In a subgroup of 45 selected on the basis of right or left extremity, these correlations were .79 and -.65 .
\end{abstract}

Wilson and Wadsworth (1972) have suggested that research on authoritarianism including the original studies (Adorno, Frenkel-Brunswick, Levinson, \& Sanford, 1950; Frenkel-Brunswick, Levinson, \& Sanford, 1947) has tended to focus on the hostility of the right-wing authoritarian and to obscure the possible equal hostility of the political left. In the original study, those who scored high on the F-scale, a presumed measure of the personality trait of authoritarianism, also tended to be conservative in political philosophy and to be prejudiced toward minority groups.

One purpose of the present study was to show that the California F-scale, which is widely interpreted as a measure of a generalized personality disposition predisposing toward hostility or prejudice, may actually correlate either positively or negatively with actual specific prejudices depending on the target in question. In other words, it was predicted that the F-scale would correlate positively with prejudice toward some targets and negatively with prejudice toward other targets.

The authors reject the interpretation offered by the original investigators (Adorno, Frendel-Brunswick, Levinson, \& Sanford, 1950; Frenkel-Brunswick, Levinson, \& Sanford, 1947) which views the F-scale as a measure of an underlying personality characteristic which also correlates with prejudices. Rather, these authors agree with Shils (1954), Christie (1954, pp. 129-133), and Rokeach (1960) that the F-scale

The second author was an undergraduate student enrolled in directed research under the supervision of the first author. He collected the data and participated in the planning of the study and in the writing of early drafts. The third author participated in the planning of the study, the writing of the early drafts, and the writing of the final draft. cannot be appropriately interpreted as a politically or attitudinally neutral measure of personality because it contains so many ideological statements-not to mention many straightforward attitude items pertaining to businessmen, professors, and homosexuals, among others.

A second purpose of the present study was to show that liking for certain groups rather than being predictive of a benign objectivity or altruism is, in fact, predictive of prejudice toward other groups. In other words, it was predicted that prejudices toward certain targets would correlate negatively with prejudices toward other targets. In making this prediction the writers reject any theoretical interpretation which holds that those with high F-scores are necessarily generally hostile and that those with low F-scores are necessarily generally altruistic and free of hostility and prejudice.

\section{METHOD}

Subjects

The subjects were 115 undergraduates, mostly juniors and seniors, enrolled in sociology and psychology classes at the University of Alabama.

\section{Measures}

(1) Form 45-50 of the California F-scale with Item 22 omitted because of its irrelevance to contempory society.

(2) A measure of right-wing prejudice based on six items prepared by the authors as likely to appeal to right-wingers. The exact items were as follows: (a) Policemen make a vital contribution to the welfare of U.S. society by preserving the public peace and providing protection to persons and property. They should therefore be respected and supported by the citizenry. (b) All sane, normal, decent persons realize that the military is vital to the preservation of our country and are willing to serve when called. (c) The first job of a college administrator is to keep order on campus and they should- 
and we should respect them when they do. (d) Militant students who create disorder and disrupt the educational process on university campuses should be expelled. (e) Negroes in the U.S. could substantially improve their standing if they complained less and worked more. (f) History will prove that many of the social, economic, and political changes brought about by the NAACP will eventually do more harm than good in the U.S.

It may be noted that a person obtains a high right-wing prejudice score by agreeing that policement, the military, and college administrators are good and that militant students, Negroes, and the NAACP are not good.

(3) A measure of left-wing prejudice based on six items prepared by the authors as likely to appeal to left-wingers. The exact items were as follows: (a) Police brutality is actually much worse than many other so-called crimes, and should be punished severely. (b) The U.S. military is an evil and repressive force and should be resisted in every possible way. (c) College administrators like Hayakawa, who take a negative attitude toward student dissenters, unnecessarily repress students and should be fined if not imprisoned. (d) Campus militants are doing a good job in the U.S. and deserve more respect and support. (e) Negroes in this country have struggled valiantly in the face of injustice and brutality and any fair-minded person admires them for their courage. (f) The NAACP is largely responsible for bringing about many social, economic, and political changes which were long overdue in the U.S.

It may be noted that a person obtains a high left-wing prejudice score by agreeing that policemen, the military, and college administrators are not good and that militant students, Negroes, and the NAACP are good.

An effort was made to keep the left-wing and right-wing scales congruent with the $\mathrm{F}$-scale in several major ways. It may be noted that most of the F-scale items refer at least vaguely to some target group. The left-wing and right-wing measures follow this same format in that you earn a maximum score by agreeing with favorable statements about some groups and unfavorable statements about other groups. The left-wing and right-wing scores were based on parallel but oppositely worded items, so that in one case right-wingers are expected to get high scores and in the other case leftwingers are expected to get high scores. It was not feasible to merely score the very same items in an opposite way to give a left-wing vs. a right-wing score, because this procedure would have resulted in an artifactual correlation of 1.0 between the two scores. All of the terms were endorsed on a six-point scale of: strongly agree, agree, barely agree, barely disagree, disagree, and strongly disagree.

In the case of both the F-scale and the left-wing and rightwing scales of the present study, all items are worded so that the subject shows prejudice by agreeing-either that some group is good or that some group is not so good. The rightand left-wing scales were done in this way so that acquiescence response bias (if any) would be the same in all three scales.

\section{RESULTS AND DISCUSSION}

The F-scale correlated .70 with the measure of rightwing prejudice and -.25 with the measure of left-wing prejudice. These findings clearly confirmed the first prediction, which was that the F-scale would correlate positively with prejudice toward some targets and negatively with prejudice toward other targets. Naturally enough, the individual items and logical smaller subgroups of items also correlated in the expected direction with the F-scale. For example, the sum of the three items praising the police, the military, and college administrators correlated .61 with the F-scale. The sum of the three items praising militant students, Negroes, and the NAACP correlated -.34 . Those items critical of the first trio of groups correlated .66 with the F-scale, and those critical of the second trio of groups correlated -.08 . In other words, the F-scale correlated positively with prejudice toward the one trio: militant students, Negroes, and the NAACP; and negatively with prejudice toward the other trio: police, the military, and college administrators.

The development and scoring of the left-wing and right-wing measures, of course, assumes that attitudes toward the two trios are, in fact, negatively correlated. The authors believed that there was a political attitudinal continuum with those liking the one trio and disliking the other at the one extreme and those with opposite likes and dislikes at the other extreme. Attitudes toward the two trios of groups were, in fact, negatively correlated. The correlations among the halves of the left-wing and right-wing measures ranged from .25 to .61 , with the direction of the correlations, of course, reflecting the direction in which the items were worded. The scoring of the two six-item measures merely capitalizes on the negative relationship between the attitudes toward the two trios of targets. As already indicated, the left- and right-wing scales were designed and scored so as to create measures that would parallel the F-scale in that a subject would obtain a maximum score by agreeing that some targets are good and others bad. In toto, the left-wing and right-wing measures correlated -.46 .

These results clearly confirmed the second prediction, which was that prejudice toward some groups, in this case campus militants, Negroes, and the NAACP, would correlate negatively with prejudice toward other groups, in this case police, the U.S. military, and college administrators.

Although satisfying in a number of respects, the results were unsatisfying in two respects. It is true that the subjects were polarized in the sense of favoring the one trio of groups and not the other or vice versa, but this polarization was not very great, as suggested by the moderate correlation of -.46 . This outcome led to curiosity about what would happen in the case of a more polarized group.

For this purpose a subgroup was selected from the larger sample. This subgroup consisted of those 45 subjects who had the greatest amount of difference between their scores on the right-wing vs. the leftwing measure. In other words, these were individuals who really liked one trio of groups and disliked the other or vice versa. In this special group, 20 were low in right-wing prejudice and high in left-wing prejudice and 25 showed an opposite pattern. With but one exception, all 45 subjects were above the median on one measure and below the median on the other. In 
the great majority of cases, they were in the top third on one measure and in the bottom third on the other measure. It may be noted that many of the conclusions drawn in the original authoritarianism studies came from the scrutiny of a sample selected in large part on the basis of its extreme hostility toward ethic groupstargets likely to be disliked by political conservatives. The procedure of the present study seems similar, except in this case the investigators considered both likes and dislikes as well as a wider range of target groups when making the selection.

Within this select group, the artificially inflated correlation between the left-wing and right-wing measures was -.80 , still not terribly high. It is appropriate to observe, however, that the student body at the University of Alabama is not noted for including all extremes of the political spectrum.

It must be noted that this most polarized subgroup was not selected on the basis of their F-scale scores. The correlations between the prejudice scores and the F-scale were, however, strongly affected. Right-wing prejudice now correlated .79 with the F-scale, while left-wing prejudice correlated -.65 . It is completely congruent with the model offered here that these correlations with the F-scale would be higher in a more polarized group.

A second unsatisfying aspect of the results was that, in both the total group and the subgroup, an asymmetry was still apparent in that right-wing prejudice correlated more strongly with the F-scale than did left-wing prejudice. The moderate correlation between the two types of prejudice, of course, allows for very different correlations with third variables. This differential correlation could presumably have come about for any number of reasons. Subtle nuances in wording, for example, may have caused the right-wing prejudice scale to be more like the F-scale, or it may be somehow relatively easy for right-wingers to praise police and blame militants (as in the right-wing measure), but relatively difficult for left-wingers to blame police and praise militants (as in the left-wing measure).

Correlations between two measures are, of course, also affected by the reliability of the individual measures. The internal consistency reliabilities of the different scales were determined by applying the Spearman-Brown prophecy formula to the average interitem correlation. These calculations were done separately for the total sample and for the more polarized subsample. The results indicated, indeed, that the left-wing measure was somewhat less reliable than the right-wing measure and that this accounted in part for the lower correlation between the F-scale and the left-wing measure.

In the total sample the reliability was .77 in the case of the right-wing measure, .62 in the case of the leftwing measure, and .86 in the case of the F-scale. Once the reliabilities were known, it seemed of interest to correct the correlations for attenuation. In the total sample, the F-scale then correlated .86 with the rightwing measure and -.34 with the left-wing measure. The right-wing and left-wing measures correlated -.67 with each other.

In the polarized sample the reliabilities were $.90, .67$, and .86 in the case of the right-wing measure, the leftwing measure, and the F-scale, respectively. When the correlations were corrected for attenuation, the Fscale then correlated .90 with the right-wing measure and -.86 with the left-wing measure. The corrected correlation between the left-wing and right-wing measures was 1.03. Unattenuated correlations can, of course, fluctuate above 1.0 due to error variance. The very high negative correlation in this case is only natural, since the members of the subsample were chosen on the basis of their disparity on the rightwing vs. the left-wing score. It certainly should be appreciated that these are unattenuated correlations based on a select sample. The select sample, however, consisted of over one-third of the total sample, and the initial sample of college students was probably not terribly extreme in any respect. The extremes of the U.S. population would probably show these same trends even more vividly.

The high unattenuated correlation of -.86 between the F-scale and the left-wing prejudice measure (in the subsample) is perhaps the most informative outcome of the present study. The idea that the F-scale measures a personality trait characteristic of the prejudice prone only does not seem compatible with a high positive correlation with some prejudices and a high negative correlation with others. The idea that the scale measures a personality trait of "authoritarianism of the right" (Rokeach, 1960) hardly seems to clarify matters. The present writers do not think such correlations are easily explained in personality terms. The present study shows that the F-scale correlates very highly with scales which are presumably composed of straightforward attitude items. Perhaps the F-scale should, therefore, be interpreted as being itself an attitude scale.

In an earlier paper, Wilson and Wadsworth (1972) favored an explanation of the likes and dislikes of leftwingers and right-wingers in terms of ethnocentrism (ingroups and outgroups). The ethnocentrism of the political right is well known both from the original studies and from much subsequent work (for example, Campbell \& McCandless, 1951). Ethnocentrism can be said to consist of xenophobia (fear and/or hatred of the strange or the stranger, that is, the outgroup) and ethnophilia (love of the ingroup as shown, for example, by patriotism). Wilson and Wadsworth (1972) suggested that the liberal person, although not ethnocentric, was not necessarily free of prejudice and hostility but rather inclined toward what might well be called xenocentrism, consisting of xenophilia (love of the outgroup) and ethnophobia (fear and/or hatred of the ingroup). In a 
somewhat similar vein, Campbell (1965b) has mentioned the xenophilia so often noted among anthropologists (and other social scientists) and has suggested that such xenophilia may be a sympton of a more basic ethnophobia. Campbell (1965a) has also noted that the xenophobia of the ethnocentric person goes hand in hand with ethnophilia, as evidenced by a willingness to defend the ingroup.

We believe that the concepts of ethnocentrism and xenocentrism can incorporate the present results, but only by putting considerable strain on the concepts of ingroup and outgroup. Since outgrouper carries the connotation of stranger or foreigner, it is awkward for ingroup vs. outgroup conceptions to explain the present data. We do not think, for example, that the person with a high F-score favors the college president over the student militants or police over Negro rioters because one group is more or less foreign than the other.

An interpretation in terms of social class is also tempting. Lerner $(1969$, pp. 607-614) has suggested that one hates one class up as well as one class down, and that the natural alliance is between people a class apart who hate the people in the middle for different reasons. Very much in line with Lerner's point is the recent suggestion by Rusher (1975, especially p. xxi) that currently the basic economic division in this country puts the (mostly middle class) producers-businessmen, manufacturers, hard-hats, blue-collar workers, and farmers-against a new and powerful class of nonproducers comprised of a liberal verbalist elite composed of the media, major foundations and research institutions, the educational establishment, the federal and state bureaucracies, and a semi-permanent welfare constituency which, it may be noted, helps to justify the existence of several of the other liberal groups. In a similar vein, Phillips (1975, especially p. 3) speaks of southerners, ethnics, and blue-collar workers vs. suburban liberals, skilled professionals, collegians, and their minority group allies. These analyses certainly are compatible with the fact that, in the present study, some students favored the Negroes with their presumably lower-class image and also campus militants with their presumably upper-class elitest image. These same students tended to oppose the police and the military with their presumably middle-class image.

It seems to us, however, that an interpretation in terms of socio-economic class distinctions also fails to be completely satisfying. Rusher's (1975) interpretation, for example, speaks of producers vs. nonproducers, and this distinction is different from class distinctions as they are usually made; for example, some producers are poor, while others are rich. Nor does it seem comfortable to think of the college administrators of the present study as middle-class peers of the policemen.

We prefer to view the attitudes, prejudices, likes, and dislikes of our subjects in political terms. This interpretation is essentially in line with realistic group conflict theory as discussed by Le Vine and Campbell (1972). It is suggested that for various reasons people see their fortunes bound up with those of certain other individuals and groups and that, as a consequence, they develop positive attitudes toward such groups and want those groups to prosper and to have power and make decisions. This interpretation allows for the often observed fact that political coalitions form sometimes on one basis, for example, social class or type of work, and sometimes on another basis, for example, religion or race.

\section{REFERENCES}

Adorno, T. W., Frenkel-Brunswik, E., Levinson, D. J., \& SANFORD, R. N. The authoritarian personality. New York: Harper, 1950.

CAmpbell, D. T. Ethnocentric and other altruistic motives. Nebraska Symposium on Motivation, 1965, 13, 283-311. (a)

CAMPBElL, D. T. Variation and selective retention in sociocultural evolution. In H. R. Barringer, G. I. Blanksten, \& R. W. Mack (Eds.), Social change in developing areas: $A$ reinterpretation of evolutionary theory. Cambridge, Mass: Schenkman, 1965. Pp. 19-49. (b)

Campbell, D. T., \& McCandless, B. R. Ethnocentrism, xenophobia and personality. Human Relations, 1951, 4, 185-192.

Christie, R. Authoritarianism re-examined. In R. Christie \& M. Jahoda (Eds.), Studies in the scope and method of the authoritarian personality. Glencoe, Ill: Free Press, 1954. Pp. 123-196.

Frenkel-Brunswik, E., Levinson, D. J., \& Sanford, R. N. The authoritarian personality. In T. M. Newcomb \& E. L. Hartley (Eds.), Readings in social psychology. New York: Holt, Rinehart, \& Winston, 1947. Pp. 531-541.

LERnER, M. Respectable bigotry. The American Scholar, 1969, 38, 606-617.

LeVine, R. A., \& Campbell, D. T. Ethnocentrism. New York: Wiley, 1972.

Phillips, K. P. Mediocracy. Garden City, New York: Doubleday, 1975.

RokeAch, M. The open and closed mind. New York: Basic Books, 1960.

RUSHER, W. A. The making of the new majority party. New York: Sheed \& Ward, 1975.

Shils, E. A. Authoritarianism: "Right and left." In R. Christie \& M. Jahoda (Eds.), Studies in the scope and method of the "authoritarian personality." New York: Free Press of Glencoe, 1954. Pp. 24-49.

Wilson, W., \& Wadsworth, A. P., JR. Attitudes of liberal and conservative students toward ingroups and outgroups. Psychological Reports, 1972, 31, 463-470.

(Received for publication November 12, 1975.) 